\title{
LOGOEMESIS Y CULTURA TEXTOVISUAL: FIGURAS DE LA GENERACIÓN Y VISIBILIZACIÓN DEL TEXTO EN EL ARTE ESCRITO MEDIADO POR LAS PANTALLAS ${ }^{1}$
}

Daniel ESCANDELL MONTIEL

Universidad de Salamanca danielescandell@usal.es

L a cultura textovisual, entendida como la combinación en múltiples formas posibles de la imagen (presente o evocada) y del componente textual-lingüístico, ha sido parte de la tradición escrita y literaria en el mundo occidental. Se ha ido formando así un canon de poesía visual con caligramas y otras combinaciones textovisuales que tienen un fuerte anclaje ya en el Medioevo y que las Vanguardias retoman potenciando una tradición que realmente se había mantenido desde entonces $^{2}$. La libertad de la puesta en página contrasta, sin embargo, con los límites a la hora de alterar la disposición textual que se encuentra en los recursos de edición y maquetación de lectores electrónicos (como el popular Kindle de Amazon), pues estos se han desvelado como productos orientados a la lectura de prosas estandarizadas o, dicho de otra manera, texto corrido sin formato complejo. Las propias características orientadas a facilitar la lectura de estos dispositivos (como modificar el tamaño de la tipografía) pueden descolocar el texto si este es fuertemente dependiente de su puesta en página o, en este caso, en pantalla. Sería en error asumir, en cualquier caso, que toda la prosa se adapta sin problemas a estos dispositivos: cuando esta ha hecho de la disposición textual y la integración de elementos visuales, incluso los más sencillos —como las célebres páginas en completo blanco o negro, o los cambios de tipos de The Life and Opinions of Tristram Shandy, Gentleman, la novela de Sterne publicada en $1759^{3}$ - pueden representar un quebradero de cabeza para los editores de sus adaptaciones al formato de estos dispositivos ${ }^{4}$.

\footnotetext{
${ }^{1}$ Este artículo es publicado en el marco del proyecto de I+D+i «MiRed (Microrrelato. Desafíos digitales de las microformas narrativas literarias de la modernidad. Consolidación de un género entre la imprenta y la red)», referencia FFI2015-70768R, financiado por el Ministerio de Economía y Competitividad de España.

${ }^{2}$ Sobre la tradición literaria española dentro de la poesía visual desde la Edad Media hasta el ocaso de las vanguardias puede consultarse Muriel (2000).

${ }^{3}$ En el mockumentary de 2005 A Cock \& Bull Story, dirigido por Michael Winterbottom, en el que se narra un falso intento de rodar una adaptación cinematográfica de esa novela, la propia página en negro se traslada a la pantalla: cuando actores y otros miembros del rodaje hablan de ella y del contexto en el que se produce en la novela (la muerte del párroco Yorick), la imagen se funde a negro y se hace también un breve silencio antes de que continúe el diálogo.

${ }^{4}$ La única edición para Kindle que se puede adquirir (a noviembre de 2015) data de 2004 y no traslada a la pantalla estas características. Es, en cualquier caso, una edición descuidada que no ha mantenido ni siquiera las cursivas o las ilustraciones.
} 
La pantalla de estos dispositivos carece, por tanto, de la suficiente flexibilidad como para alcanzar la metáfora del lienzo sobre el que se puede dibujar libremente, lo que ha forzado que, pese a las sucesivas mejoras técnicas, cuando se afronta la imagen esta no se renderice sino que esté predibujada o, dicho de otra forma, filtrada por una digitalización que denominaremos dura en tanto que es a todos los efectos una fotografía, una imagen escaneada, sobre cuyo texto no podemos actuar. A diferencia de los textos puros en los que, en esos dispositivos, se puede seleccionar, subrayar, etc., el texto escaneado junto a la imagen se convierte en imagen y pierde su potencial de interacción.

El ordenador, pero también la tableta y el teléfono inteligente, sí pueden alcanzar ese ideal de la pantalla como un lienzo, pues cuentan con suficiente capacidad para procesar sus interfaces visuales y pantallas capacitadas para trasladarlo todo a formato de imagen, tal y como sucede desde los primeros pasos de las interfaces visuales en los sistemas de computación. La interacción con el usuario es posible a través de los mecanismos dispuestos, como el teclado y el ratón, un mando, una pantalla táctil u otros, así como imágenes complejas, vídeos o híbridos como el webcómic y formatos de imagen animada como $\mathrm{GIF}^{5}$, capacidad que resultará fundamental para dar lugar a la logoemesis, entendida esta como un proceso de visibilización, presencialidad y emergencia textual.

Partimos de la logofagia descrita por Túa Blesa (1998; 2011), una clasificación tropológica de la tachadura y la negación textual; esto es, de los mecanismos que a través del arte visual, la intervención artística y la alteración tipográfica permiten invisibilizar y negar el acceso al texto a los receptores potenciales para dar lugar, de este modo, a una recepción intervenida y una experiencia estética visual y textual alterada. Mediante estas técnicas ${ }^{6}$ el texto es devorado, o como también refiere Blesa, silenciado:

El texto logofágico es un desafío y una supresión de la ley textual, que lo instituye texto y no texto, texto-y-no-texto. En él, lo externo, el silencio, se ha interiorizado, o bien lo interno, el discurso, se ha multiplicado y diseminado, o, diciéndose en una habla que no es la lengua, sin lengua, se ha disuelto: el texto-intexto (1998: 16).

Las técnicas de la logofagia, como figuras literarias textovisuales, son muchas y van más allá de las enumeradas por el propio Blesa, si bien debemos tener en consideración que él mismo ya lo señaló (1998: 17), lo que explica que la cuestión fuera retomada de forma profusa en 2011 introduciendo novedades, aunque manteniendo la orientación teórica que se estableció en el primer estudio al tiempo que se profundiza en la representatividad misma del objeto artístico cuando esta es lenguaje. Como ya sucedía en el anterior texto, se transita un espacio de hibridación entre lo literario y lo visual, pues «sucede que no son pocas las piezas en el arte contemporáneo en las que lo lingüístico no es que forme parte de la obra, sino que llega a ser todo lo que el texto artístico presenta» (Blesa, 2011: 18). Entre

\footnotetext{
${ }^{5}$ Formato gráfico usado para imágenes estáticas y, sobre todo, en movimiento. Su nombre significa Graphics Interchange Format. El formato fue creado por CompuServe en 1987 para dotar de un formato de imagen a color sus áreas de descarga de ficheros, con un límite de 256 colores (lo que afecta a su calidad de imagen).

${ }^{6}$ La clasificación desarrollada por Blesa y sintetizada en las conclusiones incluye las siguientes figuras (por orden alfabético): adnotatio, ápside, babel, criptograma, fenestratio, hápax, leucós, lexicalización, óstracon y tachón. En las páginas siguientes haremos referencia a varias de ellas, explicándolas brevemente cuando sea necesario.
} 
los dos libros, Blesa establece un catálogo de obras con las que ejemplifica su análisis de recursos para la imposición del silencio sobre el texto mediante su negación y ocultación ${ }^{7}$.

Esta combinación de arte visual (imagen) y arte literario (palabra) debe interpretarse desde la superación de la «vieja pugna entre estudios de historia del arte vs. estudios de literaria (o si se prefiere estudios sobre la imagen y estudios sobre el texto» (R. de la Flor, 2009: 87), algo mucho más necesario todavía cuando se incorporan los elementos hipermedia ${ }^{8}$ a estas creaciones y las pantallas aportan una capa adicional de mediación tecnológica entre creador y receptor de tal forma que la interacción produce reacciones cinéticas que tienen como consecuencia la visibilización del texto, esto es, su materialización ante el receptor. No en vano, en el mundo contemporáneo la imagen es en sí misma ubicua y se proyecta en mil pantallas partiendo de una «condición puramente mental, fantasmagórica, espectral» (2010: 68): la imagen se materializa cada vez desde la nada y es cada vez igual o diferente. Y junto con la imagen, la relación íntima y en ocasiones simbiótica e indivisible de esta con el texto, es decir, la textovisualidad.

La presencialidad del texto se ha hecho más evidente si cabe en las producciones audiovisual contemporáneas en lo que es un reflejo del regreso de la comunicación escrita a un plano fundamental en el día a día. Cine y televisión tenían al texto como imagen (es decir, sobreimpresionado en pantalla) situado en un papel fundamentalmente no diegético, es decir, el de los créditos o como recurso para permitirnos entender qué dicen personajes en otro idioma a través de los subtítulos. Sin embargo, en los últimos años se han multiplicado sensiblemente los usos del texto sobreimpreso con función diegética ${ }^{9}$, integrándose de hecho como parte habitual de los recursos narrativos de producciones populares, síntoma inequívoco de que esta función ha sido asimilada por las masas. En la serie Sherlock, estrenada por la BBC en 2010, son habituales las sobreimpresiones de mensajes de texto (en detrimento del recurso mucho más frecuente hasta entonces de enfocar la pantalla de un móvil), pero también de ideas que asaltan al protagonista para representar virtualmente en la pantalla su flujo de pensamiento: imágenes sobreimpresionadas a toda velocidad en el televisor, a diferentes tamaños, construyendo una nube cada vez más densa que sirve como recurso gráfico para mostrar al espectador no solo lo que piensa Sherlock, sino lo ágil de su mente, o las ideas que extrae al ver una prueba o una persona. Desde entonces es común rastrear en series de éxito usos similares del texto sobre la pantalla,

\footnotetext{
${ }^{7}$ La negación total de la obra se ha dado también a través de recursos de censura y destrucción del patrimonio textual - proceso que, entre otros, ha estudiado recientemente Pron (2014) - aunque hay una diferencia fundamental que no debe ser ignorada: en la logofagia subyace la búsqueda de la creación de un nuevo objeto artístico mediante la intervención sobre textos ya existentes o bien aplicada a textos concebidos ex profeso; en las censuras y destrucciones, en cambio, el objetivo último es la erradicación misma del testimonio de la obra o de su autor.

${ }^{8}$ Conjunto de métodos o procedimientos empleados para diseñar contenidos que tengan texto, vídeo o audio de manera combinada, con la posibilidad de interactuar los usuarios.

${ }^{9}$ Esto no significa que el fenómeno sea reciente. Por ejemplo, la serie de televisión Batman (1966-1968) usaba onomatopeyas a toda pantalla en las peleas trasladando parte del lenguaje del cómic e integrándolo como uno más de sus recursos audiovisuales.
} 
como House of Cards en su versión estadounidense (estrenada en 2012) ${ }^{10}$, ratificando así el alcance pop de la cultura textovisual ya plenamente normalizada en producciones de éxito entre el público general en las que el texto recupera su valor diegético, perdido desde el ocaso del cine mudo.

Con el foco de atención puesto esencialmente en la web y sus tecnologías afines, entendemos la logofagia como una continuación del proceso de negación, encriptación y ocultación del texto a través de los recursos de intervención y configuración textual, preferiblemente si van más allá de la «tachadura» ${ }^{11}$. Consideramos mucho más relevantes intervenciones textuales como las que realiza el Redaction Bot de Jeffrey Thompson en Twitter, una cuenta en esta red social programada para aplicar la censura de forma aleatoria a tuits que son escogidos también azarosamente entre los últimos mensajes publicados por los usuarios de la red social y son reenviados como propios con resultados como el que sigue, seleccionado el 21 de agosto de 2015: «12

is

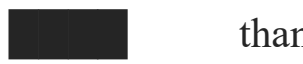

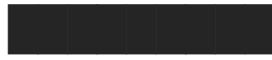

for

my

》. Cada uno de los caracteres de una palabra censurada es sustituido por un bloque negro produciendo maquinalmente, a través de su programación basada en el azar, la negación textual a través de la figura del tachón (digital). En la pantalla esta opción tiene más fuerza y carga visual que el leucós (el espacio en blanco evocador del silencio), algo relevante para la carga plástica que se asocia a la textovisualidad de la intervención logofágica.

El criptograma, figura logofágica en la que «se utilizan bien signos convencionales, usados con diferente valor del convenido, bien inventados, como sustitutos de letras, sílabas o palabras» (Blesa, 1998: 220) puede asumir una función muy similar en el espacio digital a través del lenguaje leet, es decir, el tipo de escritura con caracteres alfanuméricos usado por algunas comunidades y usuarios de diferentes medios de Internet. Esta escritura se caracteriza por sustituir los caracteres alfanuméricos estándar usando símbolos y números como sustitutos tomando como referencia una ligera similitud gráfica. Por ejemplo, leet se escribe, en su propia codificación, 1337 y, en una codificación algo más compleja, la letra «m» se representaría con la cadena «|V|» o cualquiera otra de las combinaciones comunes entre la comunidad que comparte este sistema de sustitución para enmascarar sus textos.

Más relevante es el componente visual e interactivo de la obra del poeta y artista canadiense Jason Edward Lewis ${ }^{12}$ publicada en la tienda digital de aplicaciones informáticas de Apple para sus

\footnotetext{
${ }^{10}$ El fenómeno de representación de mensajes de texto se ha dado también en la serie británica Married Single Other (2010) y en Gossip Girl (2007-2012), aunque sin tanto impacto en la estructura narrativa; de hecho, ha habido recursos similares empleados ocasionalmente en la veteranísima telenovela australiana Neighbours, estrenada en 1985 y todavía en antena. El primer uso de representación en pantalla de texto diegético como traslación de mensajes SMS se encuentra en la japonesa All About Lily Chou-Chou (2001) dirigida por Shunji Iwai. El uso diegético como parte del proceso intelectual de un personaje se puede encontrar ya en Ferris Bueller's Day Off (1986) y su ruptura de la cuarta pared.

11 Ciberpragmáticamente su uso está centrado en la blogosfera en la marcación de correcciones textuales, dejando testimonio del texto sustituido, de forma que este siga siendo legible pero se entienda que se evoca una corrección a mano sobre la metáfora del papel que es la pantalla. No tiene, por tanto, vocación logofágica plena y es una intervención tipográfica estándar en la web y en casi todos los procesadores de texto. Connotativamente, puede implicar una ligera e impostada autocensura con motivación humorística.

${ }^{12}$ La obra de Lewis (así como su proyecto artístico P.o.E.M.M., que combina instalaciones con aplicaciones digitales) ha sido estudiada desde la perspectiva de la poesía táctil por Corral (2013). Su producción resulta clave para el desarrollo de la logoemesis por su carácter híbrido y su experimentación desde hace ya varios años con las interfaces con el texto como objeto artístico principal dentro de las capacidades de intervención de los receptores en su arte.
} 
dispositivos móviles con sistema operativo iOS, como el iPhone, ha utilizado tanto la juntura extrema de palabras para invisibilizarlas creando una masa informe e ilegible ${ }^{13}$ (Know, 2011) como la potencia cinética de la pantalla para que su rápido movimiento logre un efecto similar: en No Choice About the Terminology (2012a) cada línea se mueve en un sentido (de izquierda a derecha o viceversa) a toda velocidad: el texto está, pero su movimiento lo arrastra y fuerza hasta dificultad enormemente su recepción. La velocidad se convierte en lo que podríamos introducir como la figura logofágica del hormé (óp $\mu$ )́, esto es, un «ímpetu» o «rápido movimiento de avance» que permite llegar a la ocultación textual, pese a que este no haya sido tachado o intervenido por otras técnicas gracias al dinamismo de la imagen en movimiento.

De hecho, en la pantalla pueden ejecutarse igualmente técnicas de tachadura como la superposición de capas (de imagen o texto o múltiples combinaciones), si bien la holografía supone retos adicionales al trascender la pantalla pero seguir siendo imagen virtual. Esta cuestión fue abordada en relación a la holopoesía de Eduardo Kac:

El poeta-artista, que imagina y materializa holopoemas, se sitúa en los confines de lo prohibido, muy cerca, y también muy lejos, de las convenciones poéticas. Su postura es la de «autoinmolación», de trance, de reconstrucción y de descomposición. [...] Esto es así, ciertamente, porque las letras individualizadas de los holopoemas se presentan ante nuestra capacidad visual contorneándose agitadamente, asociándose de manera vertiginosa en resultados paralelos y exigiendo al lector-espectador una especial destreza para acotar este género de arte visual. Las leyes que predominan en el entorno de los holopoemas varían considerablemente con respecto a las que hemos adquirido por tradición en la escritura impresa. Necesitan de las tres dimensiones, pero también de un creador diestro para sumergirse en un proceso de recuperación que adelante las respuestas ofrecidas por los consumidores para engendrar, así, su holotexto (Vilariño, 2010: n. p.).

Las intervenciones logofágicas sobre el holograma son similares en su pulsión a las de la realidad aumentada o las de la realidad virtual, espacios de intervención sobre la realidad o de construcción de simulaciones de realidades, pues aportan un componente de tridimensionalidad equiparable al de la escultura física y, por tanto, alterable por elementos adicionales como la modificación de la perspectiva o la movilidad del objeto dentro de su espacio real o simulado.

Asimismo, el propio tiempo es logofágico y la materialidad misma del papel destruye y silencia el texto. El patrimonio textual perdido por el devenir del tiempo es evocado como memento mori en El libro que no puede esperar (2012), texto impreso y, por tanto, anclado en el paradigma del papel, que evidencia la destrucción inherente del libro como objeto dotado de sustancia. La celulosa — sobre todo la de baja calidad tan extendida hoy en día - se degrada de manera evidente en no demasiados años; esa aniquilación del papel y de la acción de las tintas sobre el mismo crea el característico olor

\footnotetext{
${ }^{13}$ Por tanto, y en terminología de Blesa, un tachón, esto es, un tipo de óstracon (esto es, una fragmentación textual) que se da en este caso concreto mediante la ocupación del texto «por uno o más trazos más o menos crasos, que impiden o dificultad extraordinariamente la lectura» (1998: 221). En este caso se produce por aglutinación extrema de palabras, razón por la que hemos optado por llamarlo juntura. Si la mezcolanza fuere de elementos opuestos (o, al menos, diferenciados, como imagen y texto), entonces sería una amalgama.
} 
de los grandes depósitos de libros, ese aroma que percibimos ${ }^{14}$ tiene su versión acelerada para el mundo contemporáneo en la iniciativa de El libro que no puede esperar, que otorga una esperanza de vida estimada de dos a cuatro meses a su entintado: la celulosa no se descompone, sino que la tinta se invisibiliza y destruye la antología literaria que contiene en sus páginas pues esta ha sido creada para iniciar su proceso de obsolescencia al entrar en contacto con el aire para alcanzar en última instancia un leucós total.

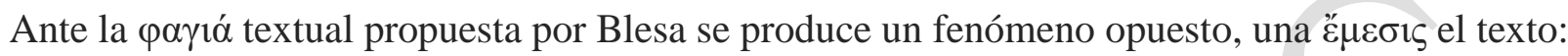
la logofagia puede producir logoemesis y devolver el texto o servir como masa crítica desde la que se inicia el proceso de visibilización y restitución de la legibilidad del texto antes silenciado. Crear ruido desde el mutismo o, lo que es lo mismo, regurgitar la textualidad antes devorada con la interacción del receptor como motor principal que impulsa los diferentes procesos de recuperación y reconstrucción textual. Las figuras de la emesis implican acción, movimiento y dinamismo: recursos textovisuales que son el resultado de la práctica artística en los soportes de la digitalidad y la virtualidad, una confluencia entre técnica y arte innegablemente productiva:

No solo porque las posibilidades de producción de formas visuales que proporcionan las tecnologías digitales de generación y tratamiento de la imagen (enriquecida por los desarrollos multimedia que acrecientan las posibilidades de su riqueza expresiva) son enormes, sino también porque sus potenciales de distribución al tejido social superan, con mucho, los de otros canales más tradicionales. Creemos por tanto que las artes de nuestro tiempo - y más aún las de los tiempos venideros- no pueden pensarse ajenas a las extraordinarias nuevas posibilidades que el escenario de las tecnologías electrónicas les proporciona y proporcionará con creces en un futuro ya muy cercano (Brea, 2007: 172).

Consideramos que el acto emético de recuperación textual implica una acción o aproximación voluntaria por parte del receptor para deshacer el texto fagocitado o suprimido para, mediante el dinamismo de la pantalla u otros medios tecnológicos para presencializar el texto; deben, por tanto, clasificarse según la actuación o el tipo de resultado. La capacidad de interacción sobre la pieza es lo que permite que la intervención del lectoespectador determine la generación o no del componente textual partiendo de una amalgama (o juntura) o de una nada real o aparente generada por una situación logofágica previa explícita o implícita para el receptor. Si retomamos la obra de Lewis antes mencionada, Know, la masa blanca que ve el usuario en la pantalla de su dispositivo es un conjunto de palabras sin forma ni fronteras que permitan la lectura. Cuando el receptor pone su dedo en la pantalla táctil, esta acción selecciona una palabra que es extraída de la masa, cambia de color a tonos violetas y se perfila un contorno que la hace plenamente legible. El efecto generado por el gesto de agarre (que podemos denominar labeín como transliteración de $\lambda \alpha \beta \varepsilon i ̃ v)$ se contagia parcialmente a otras palabras en su entorno; el texto no emerge accidentalmente, sino por intervención del receptor. En el momento en que se retira el contacto con la palabra extraída, esta inicia una nueva logofagia al hundirse

\footnotetext{
${ }^{14}$ Aroma fetichista resultado de la destrucción de la celulosa y la lignina (olor avainillado) junto a los otros componentes del libro (hojas y tapas) en combinación con la tinta. Este olor se ha comercializado a modo de ambientador cuya campaña publicitaria lo plantea como un complemento para lectores electrónicos. Su venta y publicidad se canaliza a través de la web Smell of Books <http://smellofbooks.com/> [17-11-15].
} 
progresivamente en la masa informe, perdiendo en el proceso contorno y el color hasta regresar por completo a la mancha, que es una suerte de Hades convulso que regresa a su estado de reposo original.

La misma labeín es la que se encuentra en el fondo de una de las interacciones logoeméticas principales de la edición para iPad de Pride \& Prejudice \& Zombies: The Interactive eBook (Austen y Grahame Smith, 2011), a partir del libro impreso original de 2009. El libro interactivo concebido como aplicación para iPad incluye una serie de interacciones que solo en algunos casos tienen impacto en la recuperación y visibilización textual. La mayoría de las interacciones responden a dar toques sobre la pantalla para crear una acción breve que anima una ilustración, pero también tenemos en el libro un texto ilegible por la oscuridad. En una zona de la pantalla hay un candelero (2011: 7) que ilumina tenue e insuficientemente la hoja en la que se narra esa parta del capítulo: se dota de luz a la lectura en una

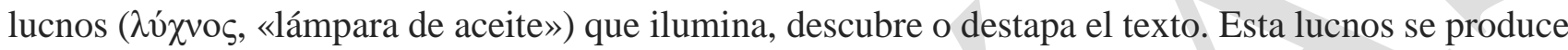
través del acto de agarrar y mover la vela es el que permite iluminar libremente la parte de la pantalla que deseemos y, así, sacar de la oscuridad el texto, en una interacción que es esencialmente esqueuomorfista ${ }^{15}$ y basada en la misma interacción táctil que antes hemos descrito ${ }^{16}$. La estrategia visual (imitar la luz de una vela) es diferente, pero la acción logoemética es la misma: agarrar un objeto (virtual) que tiene como consecuencia la visibilización al influir sobre el texto subyacente.

En el caso de la pulsión cinética de No Choice About the Terminology el texto se puede frenar tocando sobre las líneas que se mueven a toda velocidad (acción emética por eliminación del componente de movimiento que denominaremos próskomma ( $\pi \rho \sigma_{\sigma \kappa} о \mu \mu \alpha$, «obstáculo»). Al hacerlo, el texto crece descontroladamente hasta hacerse ilegible ${ }^{17}$, pero al apartar el dedo regresa a su tamaño original y con breves toques sobre cada una de las líneas se puede decelerar sensiblemente su movimiento hasta conseguir que todo el texto poémico sea legible.

El crecimiento del texto desde la nada a partir de un punto de interacción ha sido empleado por J. E. Lewis en Smooth Second Bastard $(2012 b)^{18}$, pero el efecto no se orienta al extremo de dificultar o imposibilitar la lectura, sino para permitirla generando el texto en un auxano controlado. Cada toque permite que se genere en pantalla un nuevo verso ante el lector, que determina así dónde aparece ese texto y a qué ritmo lo hace. A partir de ahí, el texto va quedando de forma residual en la pantalla,

\footnotetext{
${ }^{15}$ En referencia a la conversión en ornamento de un elemento que anteriormente era necesario pero que se mantiene no cambiar su diseño estético general. En sentido estricto, se aplica a piezas que en cerámica reproducen formas concebidas en otro material. En el ámbito de la informática hace referencia a interfaces que imitan elementos reales en entornos digitales, como un control mediante ruedas aparentemente analógicas controlar el volumen de un reproductor musical. Si tenemos en cuenta la estructura general de los sistemas operativos dominantes, su concepción es de base esqueuomórfica: carpetas, archivos, botones, etc., que sirven como metáfora de comandos y contenidos mediante una capa visual basada en objetos físicos.

${ }^{16}$ El acto inverso a la lucnos y, por tanto, logofágico en su esencia que resulta en eliminar la luz es una tyflós (del griego

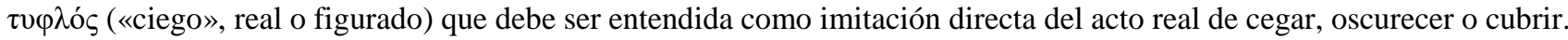
${ }^{17}$ De nuevo, un componente de movimiento que podría hacer tanto un texto ilegible por exceso (como en el caso) o legible si parte desde un tamaño mínimo, un acto de emergencia o hinchazón que en consecuencia podemos denominar auxano como transliteración de $\alpha \hat{\xi} \xi \alpha ́ v \omega$ («inflar»o «causar un crecimiento»); el efecto contrario —empequeñecer el texto- sería, en consecuencia, el nanos (vóvos).

${ }^{18}$ La aplicación se lanzó en 2012 comercialmente como producto digital limitado, por lo que ya no está disponible para su adquisición. El autor nos dio acceso a una fase preliminar beta del programa para su análisis y comentario en anteriores publicaciones.
} 
flotando y a veces creciendo, para finalmente desaparecer ante los ojos del lectoespectador. De hecho, el propio texto en ocasiones descarta palabras, que son expulsadas en la figura del othó (transliteración de $\dot{\omega} \theta \tilde{\omega}$, esto es, «empujar»). El remanente de palabras permanece visible, flotante, dando lugar a nuevos textos generados a partir de las palabras no descartadas: versos dentro de versos o textos-intexto que evocan la adnotatio de Blesa, en este caso no como vía de ocultación, sino de representación. Algo similar sucede en The World Was White (2013), también de Lewis, con una interacción de presencialización texual basada también en pulsar sobre la pantalla. Mientras la pulsión se mantiene, aparecen unas pocas palabras en una línea que pronto empieza a incorporar más y más palabras a toda velocidad mientras desplaza el texto hacia la izquierda: el texto que se suma empuja al ya presente e incluso produce un dioco ( $\delta เ \omega ́ \kappa \omega$, «destierro») textual. Al retirar el dedo el ritmo se frena y el texto es legible. La generación textual va acompañada en esta ocasión de melodía y la pantalla, completamente blanca, se entinta parcialmente de rojo mientras parpadea a gran velocidad durante fracciones de segundo ocupando casi toda la pantalla el contorno de las letras que forman el mensaje «The World Was White». El parpadeo, que parte de la nada pero como si el texto estuviera desde el principio en el vacío blanco de la pantalla, es un myopazo ( $\mu \nu \omega \pi \alpha ́ \zeta \omega$, «parpadeo») que asalta al lector con una fuerte sensación de urgencia como resultado de su acción sobre la pantalla.

Todo este componente cinético y emético que se produce mediante la interacción del receptor en

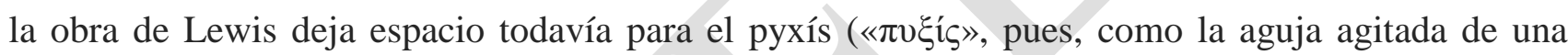
brújula, rotará buscando la dirección correcta), acción sobre el texto que permite influir en su direccionalidad y orientación a través de la rotación para alcanzar la legibilidad, pero que no se observa de forma plena en sus piezas. Esta direccionalidad sí es importante en textos de realidad aumentada, donde la rotación del punto de marcación en el mundo real (típicamente un código $\mathrm{QR}^{19} \mathrm{o} \mathrm{AR}^{20}$ ) rota también el eje del falso holograma que el receptor ve en la ilusión óptica que se genera en una pantalla y que da lugar a la impresión (dentro de la pantalla) de que un elemento virtual está en el mundo real. La dirección es relevante porque, pese a ser una creación bidimensional en la pantalla, el efecto que se persigue es el tridimensional y equiparable al de los dioramas. La rotación del soporte físico o de la pantalla-cámara (por lo general, un teléfono móvil inteligente) altera el punto de vista y visibiliza el texto del mismo modo en que se oculta en un ángulo diferente, tal y como se señalaba anteriormente en relación a los holopoemas de Kac.

Esta fisicidad de la interacción, más allá del componente táctil, tiene espacio por recorrer y posibilidades por explorar para dar más peso a la entidad corpórea del receptor. En videojuegos hemos visto cómo soplar al micrófono podía producir interacciones con el mundo sintético influyendo en personajes y entornos virtuales. En estas interacciones la voz —e incluso el bufido del usuario, que es

\footnotetext{
${ }^{19}$ Los códigos QR (quick response) son también conocidos como códigos bidimensionales. Almacenan información en una matriz de puntos cuadriculada, que puede ser cualquier texto, como una dirección de Internet que dé acceso a un contenido alojado en la web. Este sistema de códigos fue creado por la compañía japonesa Denso Wave en 1994. Se han utilizado como marcador de posición en sistemas de realidad aumentada

${ }^{20}$ Se trata de una variante simplificada de los QR cuyo nombre deriva de augmented reality. Contienen menos información, por lo que son más fácilmente leídos por las cámaras. Han sido empleados como anclajes para la localización de ítems físicos de referencia en sistemas de realidad aumentada, como libros o tarjetas.
} 


\section{Tropelías. Revista de Teoría de la Literatura y Literatura Comparada, 27 (2017)}

captado como ruido por los micrófono y codificado por el software- pueda producir reacciones en una aplicación textovisual de manera que se altere el mensaje, figura que denominamos auletés ( $\alpha \dot{\lambda} \lambda \tau \tau^{\prime} \varsigma$, «flautista»). Está más que abierta también la posibilidad del uso de huellas o datos biométricos en interacción con los sistemas computacionales de manera que se generen vías de visibilización textual capaces de trascender los controles que hasta ahora dominan las interfaces generalistas del mercado, como la detección de expresiones faciales, el pulso ${ }^{21}$, y otras que vayan más de gestos táctiles o reconocidos por cámaras. Todos los mecanismos de control y observación biométrica que se derivan de los progresos en los sistemas de comunicación entre seres humanos y máquinas tienen las mismas posibilidades expansivas en la logoemesis que los videojuegos, los sistemas informáticos o los múltiples dispositivos móviles, con independencia de su naturaleza, pues toda forma de acción tiene el potencial de generar visibilización textual.

La interacción tradicional de la interfaz visual de una computadora (es decir, el uso de un puntero controlado por un ratón o periférico afín) ha servido para permitir el uso del Telescopic Text (2010) de Joe Davis ${ }^{22}$. En esta obra el lector se enfrenta a un texto logofágico: en su pantalla aparece «I made tea» subrayado en gris. Esa marca visual indica una posibilidad de interacción: cuando pinchamos sobre cada una de esas palabras el texto se despliega y crece, clic tras clic, en el orden que determina el receptor y hasta el punto que así lo desea hasta alcanzar su máxima extensión. El texto telescópico posee una brevedad extrema aparente escondida tras la adnotatio logofágica ${ }^{23}$ y se expande en el

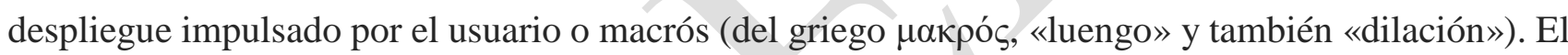
texto en su extensión plena es el que sigue:

Yawning, and smearing my eyes with my fingers, I walked bleary eyed into the kitchen and filled the kettle with fresh water from the tap, checking with my hands to make sure it was cold enough (The best tea comes from the coldest water). I glanced outside for a minute at the city mist. I could almost taste the grey. I plugged the kettle in and switched it on. As the kettle began to hiss, I looked for biscuits. Anything above loose crumbs would do. Thankfully I found some fusty digestives. For some reason, biscuits are always nicer when they've gone a bit dry and stale. I took the milk out of the fridge and poured some into a cup that I'd left out from having used earlier. The kettle began grumbling fiercely so I took it from the cord, threw a teabag into my cup and poured boiling water onto it. I watched brown swirls rise up through the muted white of milky water. A few minutes passed. I removed and squeezed the teabag, then flicked it into the bin. I picked up my mug and left the kitchen with a nice, hot cup of strong tea. (Davis, 2010)

En el espacio de lo lúdico, las intervenciones del usuario sobre el videojuego pueden dar lugar a interacciones que tengan un efecto en transmisiones textuales como la emergencia textual. Del mismo modo, el código informático puede albergar mensajes —más allá de las acotaciones o didascalias con las que un programador describe lo que va hacer esa parte de su código-, de tal forma que el propio

\footnotetext{
${ }^{21}$ Del mismo modo que rotar un dispositivo puede causar la visibilización de un texto, este puede activarse ante una respuesta biométrica, como la detección del pulso o que se estime que el usuario ha recorrido a pie una distancia determinada o que ha quemado una cierta cantidad de calorías. La biometría sería una llave de biología interna, una splankhnon ( $\sigma \pi \lambda \alpha \dot{\gamma} \gamma \chi \nu \omega \nu$, «vísceras» pero también «sentimientos»).

${ }^{22}$ El texto telescópico como logoemesis emergente fue analizado ya bajo el prisma de la logofagia y la logoemesis en Escandell (2011: 48; 2012: 279-280).

${ }^{23}$ Pues el texto está en un paratexto elidido, invisibilizado, que es el responsable de la fragmentación textual hasta su mínima expresión. No hay, en este sentido, diseminación textual como propone Blesa, sino concentración en un intratexto que se esconde tras la marca del gris que resalta el texto en la web e invita a interaccionar con él.
} 
lenguaje informático que subyace esconda los conocidos como huevos de pascua ${ }^{24}$ que se deben desenterrar, pues estos son actúan a modo de mnemeion (acción y figura que así denominamos a partir del griego $\mu v \eta \mu \varepsilon i ̃ o v, ~ « s e p u l c r o »)$. Así, en Invisible, Inc. (Klei Entertainment, 2015), un videojuego sobre hackers, los programadores escondieron en su código las instrucciones necesarias para saber cómo alterar el mismo para desbloquear un logro (que se llamaba meta-hacking). Por tanto, para conseguir este objetivo era necesario trascender el juego, explorar su código y luego alterarlo según las instrucciones que el mismo proporcionaba. Es preciso entonces desenterrar el mensaje escondido en el código mediante la intervención directa.

Los videojuegos son esencialmente audiovisuales y en la mayoría de los casos relegan el componente textual a un segundo plano en cuando a la acción (que no necesariamente en lo referente a su componente narrativo). El videojuego Bookworm Deluxe (PopCap Games, 2003), es uno de los títulos que pone en el centro de la acción las letras, algo poco habitual salvo cuando estamos ante traslaciones a la pantalla de pasatiempos clásicos como las sopas de letras o los crucigramas. Aunque algunos géneros como los MUD (multi-user dungeon) tenían en la descripción textual y las instrucciones escritas su vía de interacción (al no contar con soporte visual o ser este limitado hasta el extremo), el jugador no actuaba sobre el texto y este, en sí mismo, no era un elemento interactivo, sino la interfaz misma de uso.

Bookworm Deluxe representa una suerte de unión entre las sopas de letras y los juegos de puzles en los que las fichas caen desde la zona superior de la pantalla (cuyo modelo clásico es Tetris). El jugador debe localizar letras en posiciones adyacentes para formar las palabras de mayor extensión, conseguir que las fichas de las mismas desaparezcan, sumar puntos y que caigan nuevas fichas desde la zona superior. Según se seleccionan las letras estas se destacan hasta formar una palabra con éxito o bien pierden su destacado si la palabra no es reconocida por el diccionario interno del juego. En cualquier caso, la interacción es sobre las fichas de las letras mediante el cursor (y, en sus versiones para consolas con pantalla táctil, el dedo o el puntero imitan esa misma funcionalidad). Se pincha sobre el texto como con la lanza para marcar la letra inicial y las que la siguen.

El videojuego Typoman (Headup Games, 2015), en Wii U, propone otra forma de jugar con las palabras que es parcialmente heredera de lo desarrollado en Scribblenauts (5th Cell, 2009). Si en este título podíamos invocar objetos, animales, etc., mecanografiando palabras en la pantalla táctil de la consola Nintendo DS (es decir, escribir «caballo» genera en pantalla un equino), en Typoman podemos empujar o tirar las letras que encontramos por el escenario para colocarlas y producir acciones en el escenario, como activar plataformas («on») o provocar la lluvia («rain»). Muchos elementos del entorno son letras (las «A» son peligrosas lanzas cuando caemos sobre ellas o una montaña de «H» forma una escalera) o palabras que nos dan pistas sobre cómo avanzar, todo ello mientras controlamos a un personaje protagonista que empieza siendo una solitaria «o» que se sitúa por casualidad tras ser tirada a un vertedero con una «g» formando «go». La vocal cobra vida y podemos controlarla. Pronto

\footnotetext{
${ }^{24}$ Mensaje o contenido oculto en un software o contenido audiovisual. En programación se empleó originalmente para referirse a los mensajes escondidos en el propio código del software al que solo podía accederse desensamblando.
} 
suma una «E» que será su torso, una «H» que será sus piernas y una «r» que hace las veces de brazo: «hero». Con el cuerpo completo, se definen las acciones que a través del mando puede ejecutar el usuario a través de este personaje: correr, saltar, agarrar y lanzar. La manipulación de las letras puede realizarse a partir de cierto momento en el juego también a través de la pantalla táctil (arrastrándolas con el puntero), de manera que no hay intervención directa en el mundo sintético del juego ahorrando al jugador el acto de colocar, lanzar, empujar o arrastrar letras. Las letras son, por tanto, acción y parte del juego y se interviene directamente sobre ellas a través del héroe inserto en su mundo sintético reproduciendo así una intervención sobre el texto paralela a la del titiritero sobre su Karaguiosis ${ }^{25}$, doble entidad del usuario de todo videojuego cuando controla a su personaje-avatar.

La cultura textovisual surgida en las pantallas interactivas o capaces de intervenir y mediar sobre la fisicidad del mundo (mediante realidad aumentada) o concebir mundos sintéticos complejos (realidad virtual) ha puesto en el foco la invisibilización y visibilización textual. La negación del texto, su destrucción, es una extensión de la logofagia descrita por Blesa que en el dinamismo de la interacción ha dado lugar también a nuevas formas de erradicación mediante la interacción y el potencial cinético sobre el texto que permite la pantalla como lienzo animado y vivo. Esta misma capacidad para lo cinético es lo que, junto con las múltiples formas de interacción posibles de las interfaces de uso que existen para la relación humano-máquina, se haya dado el fenómeno contrario: la extracción, visibilización y generación textual. Desde la nada o desde textos previamente logofagocitados el texto gana presencia y cuerpo a través de un acto esencialmente emético. Aunque la textovisualidad contemporánea ya ha mostrado su capacidad para jugar con el texto en esos términos y sus técnicas han sido ya asimiladas por producciones audiovisuales populares, como las que hemos visto, el elemento diferencial de la emesis textual es el papel activo (y, por tanto, autoral en diferentes grados) del receptor. La relación entre la ocultación y la visibilización es esencialmente temporal en estos casos: la secuencia temporal es la que determina si el texto está siendo borrado o generado; hay una fuerte relación entre ambos fenómenos que hace que muchos de ellos puedan darse en un sentido o en otro, aunque a través de diferentes interacciones y mediaciones, tanto del usuario como de las tecnologías e interfaces implicadas.

\section{Bibliografía}

5TH CELL (2009): Scribblenauts [software para Nintendo DS]. Warner Bros, Interactive Entertainment. Austen, Jane y Grahame-Smith, Seth (2011): Pride and Prejudice and Zombies: The Interactive eBook, en http://www.quirkbooks.com/app/ppzapp (última consulta, 17-11-15).

BLESA, Túa (1998): Logofagias. Los trazos del silencio. Zaragoza, Universidad de Zaragoza. (2011): Lecturas de la ilegibilidad en el arte. Salamanca, Delirio.

BreA, José Luis (2007): Cultura_RAM. Mutaciones de la cultura en la era de su distribución electrónica. Barcelona, Gedisa.

${ }^{25}$ Arquetipo de personaje protagónico en el teatro de sombras clásico griego. 
(2010): Las tres eras de la imagen. Imagen-materia, film, e-image. Madrid, Akal.

Corral CaÑAS, Celia (2013): «El tacto de la poesía: P.o.E.M.M., de Jason Edward Lewis», Caracteres. Estudios Culturales y Críticos de la Esfera Digital, 2/1, pp. 96-111.

DAVIS, Joe (2010): Telescopictext, en http://www.telescopictext.com/ (última consulta, 17-11-15).

ESCANDELL MONTIEL, Daniel (2011): «Literatura digital para la enseñanza de español como lengua extranjera», Biblioteca Virtual redELE, 12, n. p.

- (2012): Narrativa digital hispana. El blog como espacio de creación literaria a comienzos del siglo XXI. Tesis doctoral, Universidad de Salamanca.

HeADUP GAMES (2015): Typoman [software para Wii U], en http://www.nintendo.es/Juegos/ Programas-descargables-Wii-U/Typoman-1025155.html (última consulta, 20-11-15).

Klei Entertainment (2015): Invisible, Inc [software para Windows/Mac/Linux], en http://store. steampowered.com/app/243970/ (última consulta, 17-11-15).

LEWIS, Jason Edward (2011): Know [software para iOS], en http://itunes.apple.com/es/app/know/ $\underline{\mathrm{id} 446777294}$ (última consulta, 17-11-15).

(2012a): No Choice About the Terminology [software para iOS], en https://itunes.apple.com/es/ app/no-choice-about-terminology/id475338554 (última consulta, 17-11-15).

- (2012b): Smooth Second Bastard [software para iOS], en http://itunes.apple.com/es/app/ smooth-second-bastard/id464978532 (última consulta, 10-09-13).

(2013): The World Was White [software para iOS], en http://itunes.apple.com/es/app/the-worldwas-white/id775138899 (última consulta, 17-11-15).

MuRIEl DuRÁn, Felipe (2000): La poesía visual en España. Salamanca, Almar.

PoPCAP GAMES (2003): Bookworm Deluxe [software para navegador], en http://www.popcap.com/ sites/www.popcap.com/prettypkg/games/bookworm/flash/1033/bookworm.html?env=live\&lcid $=1033$ (última consulta, 17-11-15).

Pron, Patricio (2014). El libro tachado. Prácticas de la negación y del silencio en la crisis de la literatura. Madrid, Taurus.

RODRíGUEZ DE LA FLOR, Fernando (2009). El giro visual. Salamanca, Delirio.

THOMPSON, Jeffrey (2013-): «Redaction Bot», Twitter, en https://twitter.com/TweetRedactor (última consulta, 17-11-15).

Trelles PAZ, Diego, ed. (2012). El libro que no puede esperar. El futuro no es nuestro. Nueva narrativa latinoamericana. Buenos Aires, Eterna Cadencia.

VILARIÑO PICOS, Ma . Teresa (2010): «Redefiniendo la poesía experimental: la holopoesía de Eduardo Kac», en Andrés Urbano, ed., El creador de seres imposibles. Manizales, Universidad de Caldas, pp. 69-74. 